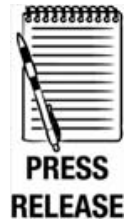

${ }^{1}$ RRMES (Institut de Recherche bioMédicale et d’Epidémiologie du Sport), Paris, France

${ }^{2}$ Université Paris-Descartes, Sorbonne Paris Cité, Paris,

France

${ }^{3}$ Inserm, Unit 970, Paris, France

${ }^{4}$ French Rugby Federation, Marcoussis, France

Correspondence to Adrien Sedeaud, IRMES, 11 Avenue du tremblay, Paris 75012 France; adrien.sedeaud@insep.fr

\title{
How they won Rugby World Cup through height, mass and collective experience
}

\author{
Adrien Sedeaud, ${ }^{1,2}$ Andy Marc, ${ }^{1}$ Julien Schipman, ${ }^{1}$ Muriel Tafflet, ${ }^{3}$ Jean-Philippe Hager, ${ }^{4}$ \\ Jean-François Toussaint ${ }^{1,2}$
}

\begin{abstract}
Objectives Toinvestigate the evolution of anthropometric characteristics in World Cup rugby players and identify elements associated with performance.

Design Age, weight and height were collected for 2692 World Cup rugby players as well as rankings in each World Cup, and collective experience of winners, finalists, semifinalists and quarter finalists in comparison to the rest of the competitors. Anthropometric parameters were compared according to age and position (back and forwards).

Results From 1987 to 2007, forwards and backs have become heavier by 6.63 and $6.68 \mathrm{~kg}$ and taller by 0.61 and $1.09 \mathrm{~cm}$, respectively. The collective experience of the forwards' pack is a value increasing with the final ranking attained, as well as the weight of forwards and the height of backs.

Conclusions For all Rugby World Cups, the highest performing teams have the tallest backs and heaviest forwards with the highest percentage of collective experience.
\end{abstract}

\section{INTRODUCTION}

The advent of professionalism in rugby was accompanied by an increase in the body size of players, ${ }^{1}$ observed either in the French championship or international matches during the Bledisloe Cup. ${ }^{2}$ This trend follows the evolution of the constraints of this activity, in which the number of tackles or rucks per game increased by a factor of 4 in 30 years. $^{2}$ Eaves and Hughes ${ }^{3}$ also showed that the incidence of rucks in five and six nations championships had increased from 62.4 events/game in 1988 to 134.4 in 2002. Austin et al $^{4}$ suggest that the development of modern rugby union has resulted in an increase in high-intensity activity and has become more physically demanding due to increases in total duration and speed of play. ${ }^{3}$ Thus, increased mass and height are desirable characteristics, such as in American football where the largest and most powerful players are selected. ${ }^{5}$ Indeed, overall size appears as a predictor of efficiency ${ }^{6}$ : a strong association exists between mass, height and the individual and collective performances. Teams with the tallest and heaviest players outperform others in the 1999 Rugby World Cup. ${ }^{6}$ However, rugby union generates many phases of contact, tackling, ruck, maul and scrum, which necessitate various physical demands ${ }^{7-9}$ requiring players to participate in intensive efforts interspersed with some periods of lower intensity. ${ }^{10}$ In fact, rugby performance involves a large number of parameters dependent on the specific constraints of the activity. Among these, strength, speed, aerobic and anaerobic power, ability to change direction and sport-specific attributes are influential. ${ }^{11}$ Performance is also related to collective efficacy. Indeed, groups with a strong sense of collective efficacy are more likely to succeed than those who do not share this particular attribute ${ }^{12}$ and maintain their group performance longer. ${ }^{13}$ In other sports such as soccer, a greater percentage of new recruits is associated with a lower number of points scored per game. ${ }^{14}$ In rugby, the score of collective efficacy has been estimated to account for $22 \%$ of the variance in positive affect in prematch. ${ }^{15}$

As rugby becomes more physically demanding, ${ }^{7}$ we hypothesised that players' mass, height and collective experience are all crucial parameters in World Cup performance progression.

\section{METHODS}

This study aimed to investigate changes in the height and mass of rugby players who took part in all Rugby World Cups and identify elements associated with higher performance.

\section{Ethics}

This study uses a research protocol qualified as non-interventional, in which '....all acts are performed in a normal manner, without any supplemental or unusual procedure of diagnosis or monitoring.' (Article L1121-1 of the French Public Health Code). According to the law, its approval therefore did not fall under the responsibility of a committee for the protection of persons (CPP). For these reasons, it is not necessary to obtain informed consent from the athletes evaluated. This study is designed and monitored by the IRMES (Institut de Recherche bioMédicale et Epidémiologique du Sport) scientific committee.

\section{Data collection}

Data for age, mass and height were collected for all players who participated in the Rugby World Cup from 1987 to 2007. Data were collected from official sites of national teams such as www.ffr.fr, www.allblacks.com and www.fijirugby.com, and cross-classified by various sources such as www. itsrugby.fr, www.lionsrugby.com or www.rugbyrama.fr. The annual version of Rugbyrama website collects official data (for age, mass and sizes) provided by the clubs. These data were derived from the longitudinal follow-up of players, with measurements done by each team physician. 

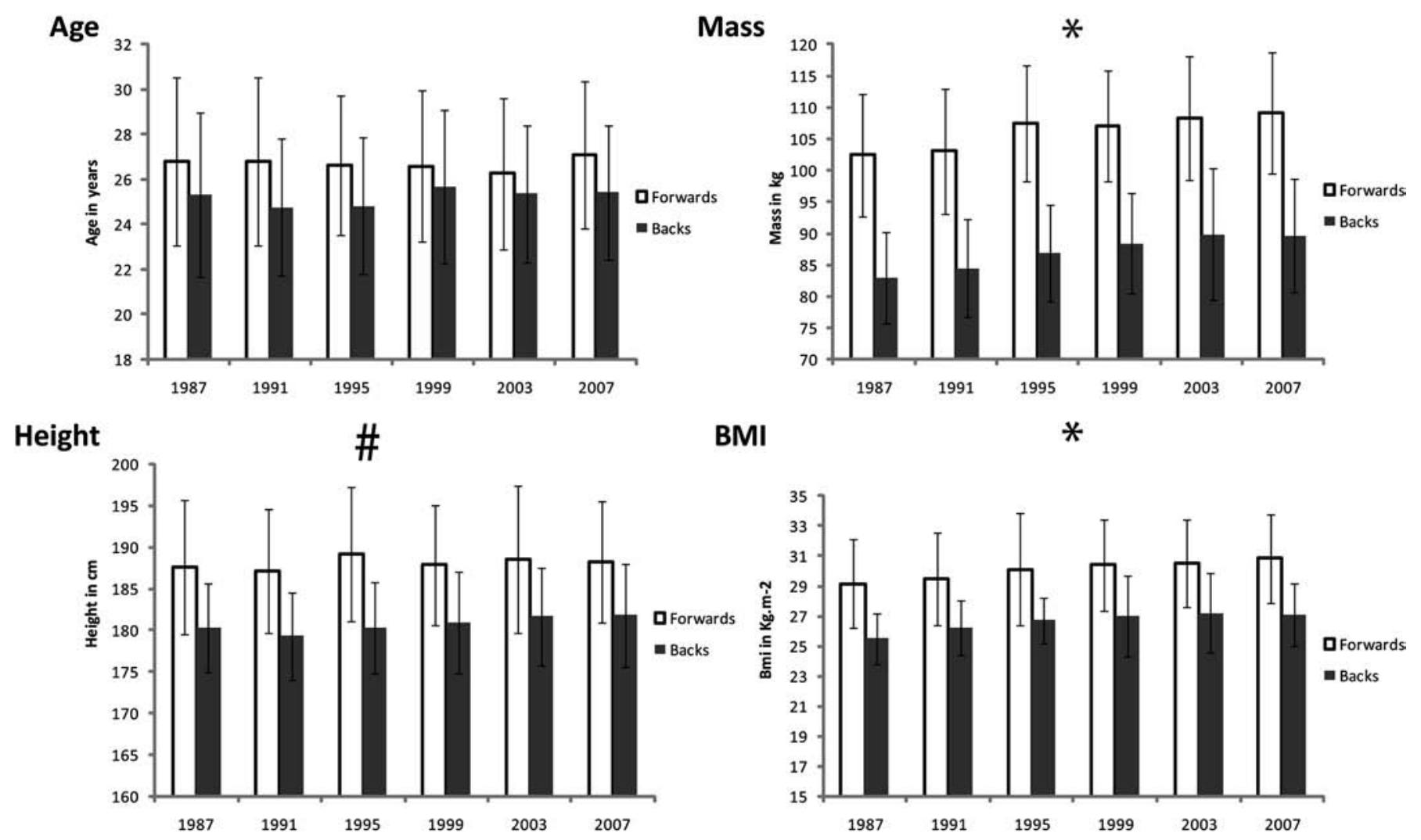

Figure 1 Evolution of the age, height, mass and BMlrepresented bymean andSD of newselected World Cupsrugby players. ANOVA*=p<0.05 for forwards and backs, ANOVA\#=p<0.05 for backs only. For all World Cups, forwards and backs were significantly different in age, height, mass and BMI.

\section{Study design}

Players were separated in two populations: backs (player numbers 9 through 15), and forwards (player numbers 1 through 8).

Each team performance was analysed according to age (in years), and biometric parameters (height in centimetres, mass in kilograms and body mass index (BMI) in $\mathrm{kg} . \mathrm{m}^{-2}$ ) of both categories.

Analysis of the entire team was performed, regrouping all players within a team, both starters and substitutes. We analysed all the selected players (starters and substitutes), as a World Cup is won with the entire team, as players get replaced within matches and from match to match.

Analyses were also carried out for international rookies (international rookies: rugby players participating for the first time at World Cup).

Collective experience was defined as the percentage of players in each team who participated in the previous World Cup:

\%of collectiveexperience forforwards =

\section{$\frac{N \text { forwardswhoparticipateinworld cupbefore }}{N \text { forwards }} \times 100$}

We analysed collective experience, such as mass and height, according to player position (back, forward) and also according to the level reached by each team: winners, finalists, semifinalists and quarter-finalists of World Cup versus the rest of competitors.

\section{Statistical analysis}

Percentages of collective experience were compared by $\chi^{2}$ test. Evolutions of biometric parameters were compared over the six World Cups, between forwards and backs, and according to final ranking. Biometric parameters between categories were compared by Student's $t$ tests. The changes of parameters between World Cups were tested using analysis of variance, and with multiple linear regression to test the time effect. The level of significance was set at $\mathrm{p}=0.05$.

\section{RESULTS}

The sample population is composed of 2692 players, including 1457 forwards and 1235 backs. New internationals include 1044 forwards and 866 backs.

\section{Evolution of internationals' rookies}

For all World Cups age, height, mass and BMI are significantly higher for forwards than for backs (figure 1).

There is a significant evolutionary trend for increased mass and BMI, for forwards and backs as well as increased height in backs. Biometric characteristics of players increase between each World Cup, by $1.34 \mathrm{~kg}$ and $0.33 \mathrm{~kg} \mathrm{~m}^{-2}$ on average for forwards, and by $1.46 \mathrm{~kg}$ and $0.30 \mathrm{~kg} \mathrm{~m}^{-2}$ for backs (table 1 ).

\section{Mass as a determinant of performance}

For all World Cups, the forwards in winners' teams, finalists, semifinalists and quarter-finalists are significantly heavier than forwards of the other teams (figure 2). Indeed the mean $( \pm S D)$ mass of forwards whose teams win the World Cup is $108.5( \pm 7.9) \mathrm{kg}$ while the rest of competitors weight only $106.1( \pm 9.3) \mathrm{kg}$. For backs, we also see this significant trend in semifinalists and quarter-finalists, but the trend did not quite reach significance for winners and finalists $(p=0.055$ and 0.072, respectively). Backs whose teams reach quarterfinals weigh $88.3( \pm 7.7) \mathrm{kg}$ while backs whose teams do not reach quarter-finals weigh $85.6( \pm 8.1) \mathrm{kg}$. 
Table1 ANOVA and linearregressionforbacks and forwards

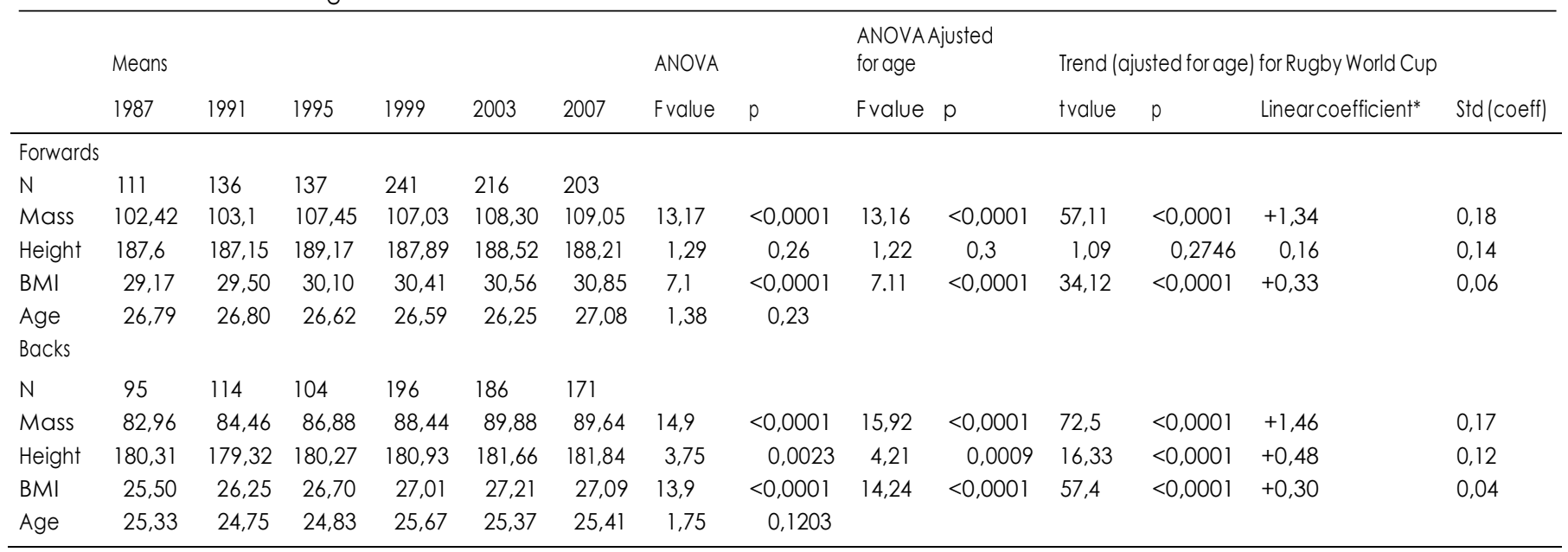

*By 4 years unit

ANOVA, analysis of variance; BMl, body mass index

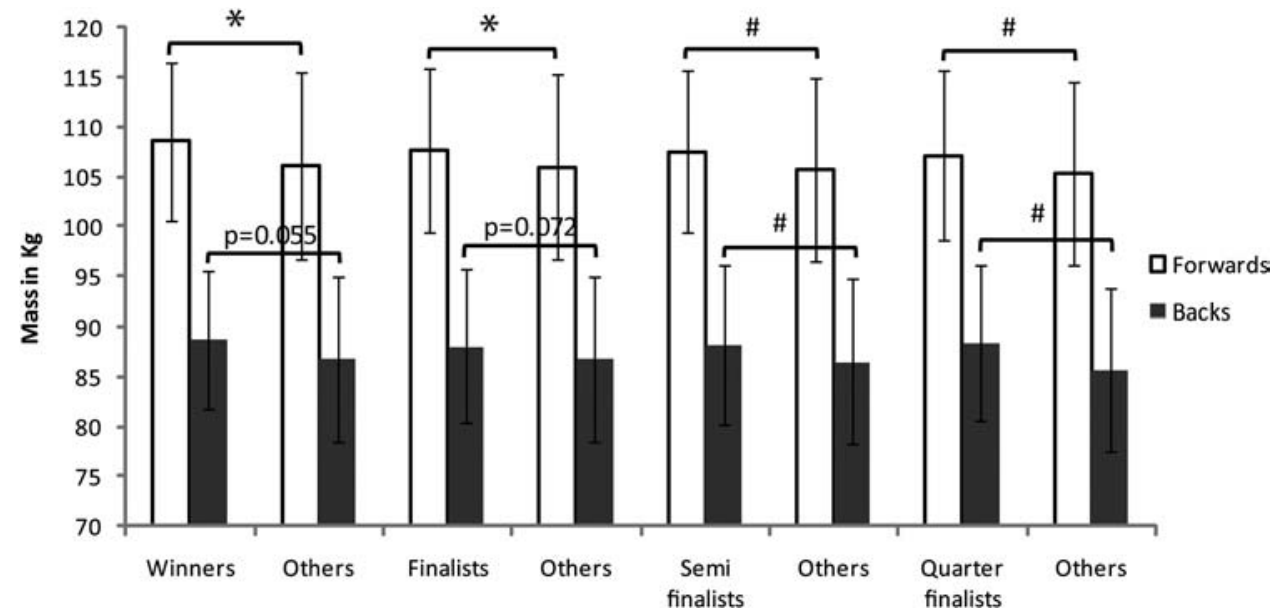

Figure 2 Mass in mean and SD of World Cups' winners, finalists, semifinalists and quarter-finalists versus rest of competitors. ${ }^{*} p<0.05$ and $\# p<0.01$.

\section{Height as a determinant of performance}

For all World Cups, the backs in winners' teams, finalists, semifinalists and quarter-finalists are significantly taller than backs of the other teams (figure 3). Indeed the height of backs whose teams win World Cup is $182.4( \pm 5.4) \mathrm{cm}$, while it is only $180.9( \pm 5.8) \mathrm{cm}$ for the rest of competitors. In forwards, we observe a similar trend that did not reach the accepted significance level (winners vs others $p=0.072$, finalists vs others $p=0.051$, semifinalists vs others $p=0.12$, quarter finalist vs others $\mathrm{p}=0.089)$.

\section{Collective experience as a determinant of performance}

For all World Cups, forwards of the winning team have a significantly greater collective experience than forwards of all other teams: $39.6 \%$ for victorious teams' forwards and $31.7 \%$ for forwards of the other teams (figure 4 ). In addition, collective experience of forwards whose teams participated in a final, semifinal and quarter-final is also significantly higher than those teams who failed to qualify for these rounds. For example, 38.1\% of finalists' forwards have already played a World Cup against $31.1 \%$ in forwards of the other teams.

\section{DISCUSSION}

In this study, we find that between 1987 and 2007, mean mass and BMI of all forwards and backs increased significantly in the Rugby World Cups. This confirms the trends observed since the introduction of professionalism, in French rugby players, or those taking part in the Bledisloe Cup, ${ }^{2}$ or emerging teams of international rugby. ${ }^{16}$ Given the constraints of the game which directs the play towards more and more physical confrontations, rugby becomes a sport where heavy players become increasingly important: the maximisation of builds and the quest for 'super-sizes' are inherent to international level rugby, as well as in other sports. ${ }^{5}$ Indeed, development of lean body mass is desirable in rugby to increase speed, strength and consequently power. ${ }^{1718}$ The increases in mass and BMI can be explained by increases in training load coupled with a nutritional follow-up, and for some and sporadically, through the use of anabolic steroids. ${ }^{19}$ Indeed, the World Anti-Doping Agency in its annual report highlights that 39 of the 5725 rugby players were tested positive. ${ }^{19}$ This low percentage suggests that this phenomenon is not more prominent in rugby than in other sports. 


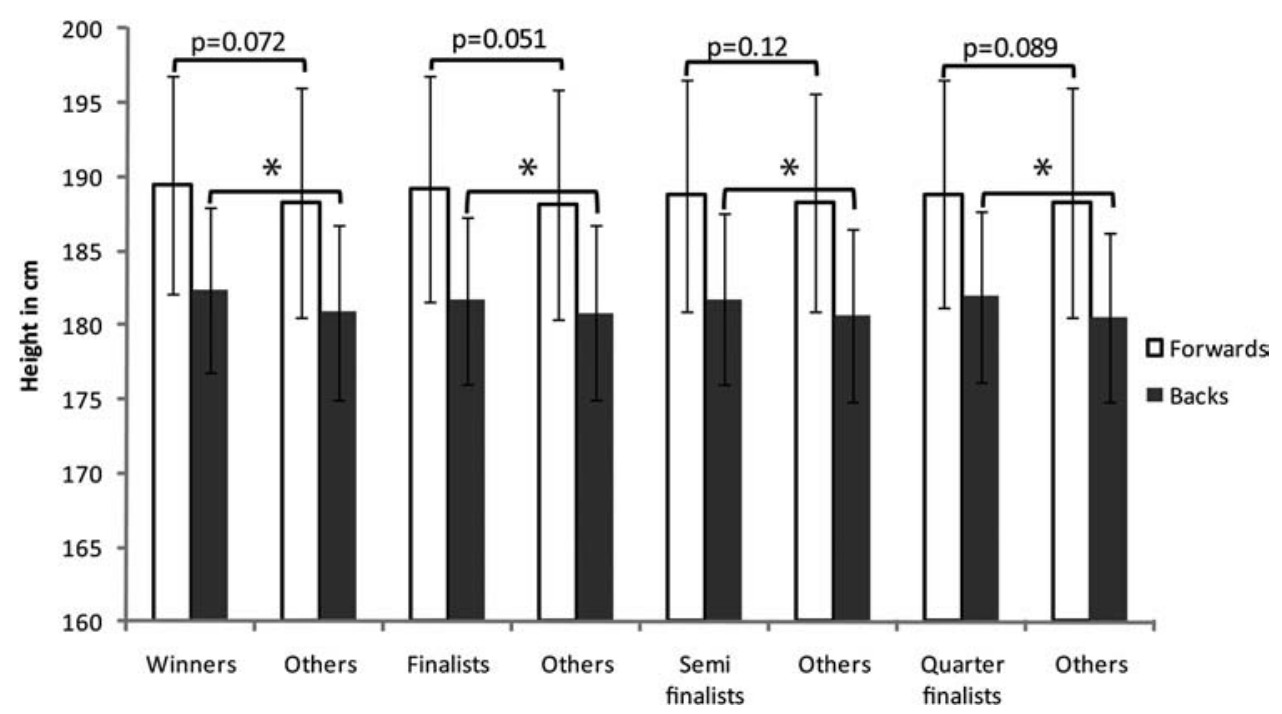

Figure 3 Height in mean and SD of World Cups' winners, finalists, semifinalists and quarter-finalists versus rest of competitors. ${ }^{*} p<0.05$.

Changing rules also drive changes in the size of players. Rules generate the game, which in turn generates the morphology requirements. Thus, the increase in physical confrontation leads to a quest for super-size players.

For all World Cups studied here, forwards were significantly older, taller, heavier and with larger BMI than backs, a result consistent with previous studies. ${ }^{1} 2021$ This is principally explained by the profile of these positions: forwards spend significantly more time tackling ${ }^{22} 23$ and in contact phases ${ }^{122}$ and high-intensity activities that backs. ${ }^{23}$ Moreover, being heavier and larger allows them to generate and tolerate greater impacts and to provide strength and power during the phases of scrums, rucks and mauls.

We show, in all World Cups, that the mass of forwards is one of the determinants of team performance in rugby. Indeed, teams who win a World Cup, or reach finals, semifinals and quarter-finals, have heavier forwards than the other teams, as already observed in the 1999 Rugby World Cup. ${ }^{6}$ In addition, we observe the same trend in backs. Rugby performance is of course more complex and multifactorial. In addition to energy resources and physical skills (strength, rate of force development, acceleration, power, endurance) considered as determinants of performance in rugby, some, but not all, of these qualities may be inherent to larger players. ${ }^{17} 18$ Indeed, as shown by Bejan et al, in many species including humans, force, speed and power increase with mass. ${ }^{24}$ Even though other skills such as dexterity, technical address, tactical and psychological qualities may be equally important, a criterion as simple as body mass remains a major parameter associated with success in the final of the World Cup.

Teams that either win a World Cup, or reach finals, semifinals and quarter-finals, are also characterised by taller backs than the others. These data are consistent with a previous study ${ }^{6}$ reporting that the 1999 Rugby World Cup finalist squads were taller than other competitors. Finding backs participating in the later matches of the tournament as taller than their counterparts can be explained by the specificities of their positions. Indeed, being taller confers advantages at the highlights of the game (ie, receptions under kicks and protection in isolated rucks in wait for the forwards' support).

Another key result of this study is showing that winners, finalists, semifinalists and quarter-finalists have forwards with a superior collective experience compared with other teams.

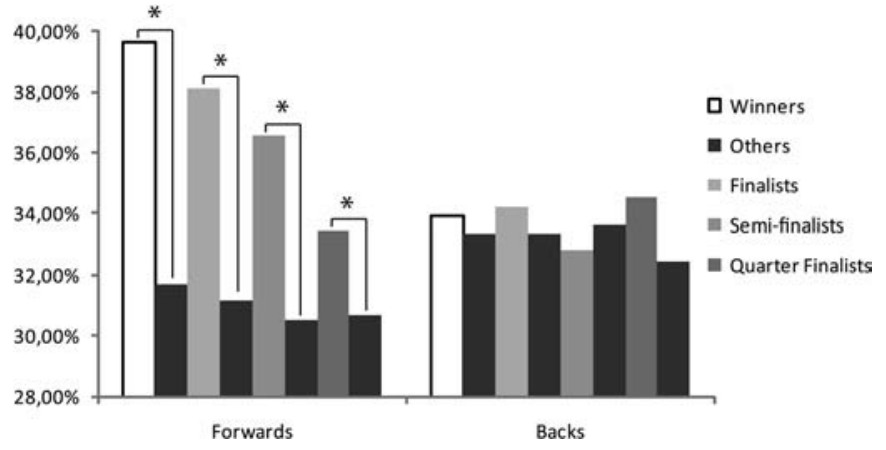

Figure 4 Percentage of collective experience by positions of teams that won, participated in a final, semifinal or quarter-final versus rest of competitors. ${ }^{*} p<0.05$.

Collective experience gained from previous World Cups and the four competition seasons between them is a performance factor for forwards. Moreover, this percentage grows from quarter-finalist teams (33.4\%) to the winning teams (39.6\%). Collective experience of forwards gives a clear advantage during phases of collective combat. The art of working together, sharing the action either on offence or defence is the essence of rugby. The collective investment and shared effort in all forwards' actions is crucial, whether in rucks to keep the ball, synchronisation during line-out, maul for placement, collective push and orientation in scrums. Containing and guiding teammates during scrums starts with a collective link, placement and work throughout the push. This element of game combines physical skill and a strong complicity, acquired over the years. Collectively adapting to adverse scrums, providing a common effort, direct scrum pressure, meeting together in a difficult situation requires a shared knowledge and combined action. This action knowledge is central to forwards' play and is apparently acquired more slowly. This may be why teams winning the World Cup have forwards with a collective experience significantly higher than those which do not win.

We show that, some factors like size and experience might be predictors of success. However, it is probable that there are other factors that explain why only four countries have ever won the Rugby World Cup. Indeed, winning teams in a Rugby World Cup may also owe their victory to their nation's economic, historical, political and technological investment in this sport. ${ }^{25}$ 


\section{CONCLUSION}

We show that forwards and backs are becoming heavier from one World Cup to the next. Although performance in rugby is complex and multifactorial, simple factors as mass and height are discriminatory in the armament race. In fact, teams with heavier forwards and taller backs perform better than others. In addition, teams that win a World Cup, arrived in finals, semifinals and quarter-finals have forwards with greater collective experience than those who do not participate in these matches.

Contributors Designed research:AS, JFT. Performed research: AS, AM, JS, MT, JPH, JFT. Analysed data: AS, AM, JS, MT, JPH, JFT. AS, JFT wrote paper which was critically revised for intellectual content by all co-authors.

Acknowledgements The authors thank Karine Schaal for proofreading the manuscript and providing valuable critique and advice. The authors thank INSEP teams for their full support.

\section{Competing interests None.}

Provenance and peer review Not commissioned; externally peer reviewed.

\section{REFERENCES}

1. Duthie G, Pyne D, Hooper S. Applied physiology and game analysis of rugby union. Sports Med 2003;33:973-91.

2. Quarrie KL, Hopkins WG. Changes in player characteristics and match activities in Bledisloe Cup rugby union from 1972 to 2004. J Sports Sci 2007;25:895-903.

3 Eaves S, Hughes M. Patterns of play of international rugby union teams before and after the introduction of professional status. Int J Perform Anal Sport 2003;3:103-11.

4. Austin D, Gabbett T, Jenkins D. The physical demands of Super 14 rugby union. J Sci Med Sport 2011;14:259-63.

5. Norton K, Olds T. Morphological evolution of athletes over the $20^{\text {th }}$ century: causes and consequences. Sports Med 2001;31:763-83.

6. Olds $\mathrm{T}$. The evolution of physique in male rugby union players in the twentieth century. J Sports Sci2001;19:253-62.

7. Brooks JH, KempSP. Recent trends in rugby union injuries. Clin Sports Med 2008;27:51-73, vii-viii.

8. Mellalieu S, Trewartha G, Stokes K. Science and rugby union. J Sports Sci 2008;26:791-4.
9 Duthie GM. A framework for the physical development of elite rugby union players. Int J Sports Physiol Perform 2006;1:2-13.

10. Cunniffe B, Proctor W, Baker JS, et al. An evaluation of the physiological demands of elite rugby union using Global Positioning System tracking software. J Strength Cond Res 2009;23:1195-203.

11. ArgusCK, Gill ND, KeoghJW, etal. Changes in strength, power, and steroid hormones during a professional rugby union competition. J Strength Cond Res 2009;23:1583-92.

12 Goncalo JA, Polman E, Maslach C. Can confidence come too soon? collective efficacy, conflict and group performance over time. Organ Behav Hum Decis Process 2010;113:13-24.

13. Greenlees IA, Graydon JK, MaynardIW. The impact of collective efficacy beliefs on effort and persistence in a group task. J Sports Sci1999;17:151-8.

14 Poli R, Ravanel L, Besson R. Annual review of the European football players' labour market 2010.

15. Greenlees IA, Nunn RL, Graydon JK, etal. The relationship between collective efficacy and precompetitive affect in rugby players: testing Bandura's model of collective efficacy. Percept Mot Skills 1999;89:431-40.

16. Babic Z, Misigoj-Durakovic M, Matasic $\mathrm{H}$, et al. Croatian rugby project-Part I. Anthropometric characteristics, body composition and constitution. J Sports Med Phys Fitness 2001;41:250-5.

17. BellW.Body composition of rugby unionfootball players. BrJSports Med 1979;13:19-23.

18. Duthie GM, Pyne DB, Hopkins WG, et al. Anthropometry profiles of elite rugby players: quantifying changes in lean mass. BrJ Sports Med 2006;40:202-7.

19 World Anti-Doping Agency. Adverse Analytical Findings and Atypical Findings Reported by Accredited Laboratories 2009.

20. Quarrie KL, Handcock $P$, Waller $A E$, etal. The New Zealand rugby injury and performance project. III. Anthropometric and physical performance characteristics of players. BrJ Sports Med 1995;29:263-70.

21 Maso F. Exigences physiologiques nécessaires à la pratique de rugby de haut niveauPhysiological features of rugby players of French team. Science \& Sports 2002;17:297-301.

22. Roberts SP, Trewartha G, Higgitt RJ, etal. The physical demands of elite English rugby union. J Sports Sci 2008;26:825-33.

23 Eaton C, George K. Position specific rehabilitation for rugby union players. Part I: Empirical movement analysis data. Physical Therapy in Sport 2006;7:22-9.

24. Bejan A, Marden JH. Unifying constructal theory for scale effects in running, swimming and flying. J Exp Biol 2006;209:238-48.

25. Guillaume M, Helou NE, Nassif H, etal. Success in developing regions: world records evolution through a geopolitical prism. PLOS ONE 2009;4:e7573. 
<smiles>C1CCCCC1</smiles> 